\title{
A Review of the Study on Father Involvement in Child Rearing
}

\author{
Xiaohong $\mathrm{Liu}^{1,2}$ \\ ${ }^{1}$ College of Education Science and Music, Liupanshui Normal University, Liupanshui, China \\ ${ }^{2}$ College of Education, Liaoning Normal University, Dalian, China \\ Correspondence: Xiaohong Liu, College of Education, Liaoning Normal University, Dalian, China. E-mail: \\ liuxiaohong0812@126.com
}

Received: April 5, 2019 Accepted: August 15, $2019 \quad$ Online Published: August 30, 2019

doi:10.5539/ass.v15n9p82 URL: https://doi.org/10.5539/ass.v15n9p82

\begin{abstract}
A large number of studies have proved that fathers have irreplaceable important value to the growth of young children. While in reality, there is a large number of "father missing" phenomenon in China. Previous studies have focused on the influence of father involvement on children development and the influence factors of father involvement in child rearing. Fathers' participation has various degrees of influence on children's development of personality, social ability, cognition, intelligence and academic achievement, gender roles, morality and emotion, as well as physical development. Family, society, fathers' characters and children's personalities all affect fathers' participation in child rearing to some extent. There are the following deficiencies in the studies of father involvement: first, the number of research on fathers' participation is very insufficient; second, the research scope of father involvement is narrow and interdisciplinary research is insufficient; third, the research depth needs to be improved urgently; Fourth, the research paradigm is mainly speculative and quantitative, and the qualitative research needs to be strengthened.
\end{abstract}

Keywords: father involvement, child rearing, review

In early childhood education, parents play irreplaceable roles in the growth of their children. Mothers give their children more living care, and fathers participate more in playing games with their kids, encouraging them to explore the outside world as well. According to Heizmann et al., children lacking fathers' love are more likely to be emotional disorder, and there are many defects such as anxiety, self-esteem and aggressive behavior. Even after being adults, they also have many bad living habits. American experts used 30 indicators of social behaviour to survey children living in families without fathers and reached a similar conclusion. They found that depression, loneliness, capricious and dependent behavior were common in these children, known as "lack of fathers' love syndrome" (Sun, 2007). In recent years, although the importance of father involvement is generally recognized by the whole society, the phenomenon of "father absence" still exists widely in China. As far as the present situation of China is concerned, fathers are more responsible for supporting families economically, while children are mainly taken care of by mothers. The Hong Kong Council for Democracy has interviewed more than 600 fathers and their children and found that $60 \%$ of them said they ignored family care because of their long working hours and lack of communication with their children (Chen, 2002). Most fathers rated themselves as unqualified or simply qualified, giving themselves the highest average of 6.4 points, lower than the average for their children to the father.

\section{The Impact of Fathers' Participation on Children Development}

Early studies on parentage mostly ignored the influence of fathers on children's growth. It was not until the end of the 20th century that researchers began to pay attention to the important impact of fathers on the development of their children (Aldous et al., 1998; Amato, 1994; Atkinson \& Blackwelder, 1993; LaRossa \& Reitzes, 1993). A large number of related studies focused on the influence of father involvement (or absence) on children's physical and mental development, and paid more attention to the role of fathers' participation in the growth of children. In summary, the important impact of fathers' participation on children development focused on the following five areas:

\subsection{The Influence on Children's Personality and Social Development}

Psychological studies have shown that recognition of parenting style and education is decisive in the initial course of a child's personality. Although fathers usually spend less time with their children than mothers, studies 
show that fathers have a greater impact on children's social and personality development than mothers. For example, Turkish family educator Gallius believes that a responsible father's care for a child has a positive effect on the child's personality development by $25 \%$ to $30 \%$ higher than that of a mother. Fathers' participation has a positive impact on children's personality and social development, mainly reflected in promoting children to form positive, optimistic and enterprising personalities, dare to take risks, and establish good interpersonal relationships. Stanley et al. (1986) used "Interpersonal Problem Solving Test for Preschool Children" to test 25 4-5-year-old children whose fathers had left longer than eight months. The results showed that these children with absent fathers lacked the ability to communicate with each other in real life. Kato, Ishii-Kuntz et al. (2002) found that father involvement in parenting had a direct impact on the development of pro-social behavior of 3 -year-old children. Children with higher levels of father involvement were more likely to have positive peer relationships and were more popular and loved. Psychologist Mike Minney's survey showed similar results: boys who had been in contact with their fathers for no less than two hours a day had better interpersonal relationships than boys who had less than six hours of contact with their fathers in a week. Tamis (2004) pointed out that the most basic role of a father in the growth of a child was as a playmate. Father-son play induced childrens' curiosity about the outside world, and successful exploration of the outside world could give them confidence and courage in face of strange environments. Chunghan Jin (2005) and Jianxiang Chen (2007) think fathers were the children's game companions, and their humor, rugged and strength would bring children infinite joy of life. In games, fathers' good personality quality such as independent, bravery and innovation can infect children, and help them to form healthy personality. The research of Shu Yu (2011) showed that the interaction and communication behavior between fathers and children and the emotional expression behavior of fathers had a significant predictive effect on the social behavior of young children.

\subsection{The Influence on Children's Cognition, Intelligence and academic Achievement}

Fathers influnce on children's cognition development starts at a very early time. Nugent's (2001) study of Irish working class families found that the higher the fathers' participation in parenting, the higher the cognitive development level of their children. Children would have higher cognitive abilities at the age of 6 months and the following year if their fathers' participation was high. In contrast, the absence of a father has a negative impact on child's cognitive development. Xia Li (2007) found that the cognitive abilities of 5-year-old children whose parents were divorced and lacked their fathers' love were different from children in normal families, which showed that they were lagging behind in the intelligence tests such as box design, labyrinth walking, arithmetic and so on. A 12-year long study at Yale University in the United States found that children brought up by fathers had higher IQ and better scores at school and were more likely to succeed in the future. A large number of studies have shown that there is a significant relationship between parent-child relationship and children's academic achievement. According to Biller (1993), children with absent fathers were more likely to suffer from maladjustment, low academic achievement, and peer tension in school, thus showing problems such as violation of discipline and criminal behavior. Henderson et al. (1994) had similar results: father involvement was closely related to increased children's attention, reduction of disciplinary problems, and increased insight. Studies by Sott (1995), Flouri (2002, 2005), Mcbride (2005) had shown that when fathers participation in children education, they played positive roles in promoting their children's academic achievement and learning attitude. It was further found that parent-child relationship did not directly affect children's academic achievement, but affected children's emotion and behavior, which had an indirect effect on learning achievement.

\subsection{The Impact on the Development of Children's Gender Roles}

The gender role is the behavior expectation that the society produces to males and females. The development of gender role is an important aspect in the development of children's socialization. Father involvement has a significant impact on the formation of their children's gender roles, the shaping of gender behaviour, and the completion of gender socialization. Sears and his wife have made a pioneering contribution to the research. They first experimented with toy games for 3-5-year-old boys whose fathers served in the army during World War II. The study found that boys with absent fathers showed weaker aggression and less gender role differences in the game than boys who had their fathers at home. Experiments conducted by Beach (1946) and Santroek (1970) on children of different ages confirmed the validity of findings of Sears and his wife. Biller (1969) divides gender roles into two parts: first, gender roles position, which means the cognition and evaluation of onselves own gender; second, gender roles preference, which makes their behavior similar to other people of the same gender. Through the comparison between families with fathers and families without fathers, it was found that the boys in the integrated families were more masculine than the boys without fathers in the orientation of their gender roles. Doherty's study showed that women who lost their fathers before the age of five often showed anxiety, shyness 
and inactivity during puberty with men. Psychologist D. Stoop (2005), in his book "Make Peace with Dad", gave a detailed account of the effects of the absence of fathers at different stages of growth in boys and girls in six sets of contrastive stories.

\subsection{The Influence on Children's Moral and Emotional Development}

The development of human morality is influenced by many factors. Therefore, scholars have different opinions on the role of fathers playing in the development of children's morality development, and explain it from different angles. Parents influence their children's moral development through their own words and deeds, their disciplines, the satisfaction of their children's emotional needs, and the connection between their children and the outside world. Parsons and Beles believe that fathers and mothers play instrumental and emotional roles in the family. Therefore, Martin Hoffman (1981) attached great importance to the role of fathers as tools in the moral development of children, and believed that fathers could influence their moral development by teaching and internalizing various norms to their children.

\subsection{The Influence on Children's Health Development}

According to the traditional conception that it is mothers' responsibility to raise and take care of their children's health, and only mothers can influence the children's health. However, it has been proved that fathers still play an important role in the development of children's health through a variety of direct and indirect factors. First, fathers can indirectly affect their children's physical well-being by keeping their mothers healthy. Second, the absence of a father makes his children more likely to have health problems. Children living in remarried and single-parent families are more likely to suffer from sudden illnesses or accidental injuries than children from normal families. Harknett (2005) found that even considering demographic and socio-economic conditions, children who did not live with their fathers were more likely to suffer from asthma or other sudden diseases caused by asthma. Trost (2001) also noted that children from single mothers family were more likely to suffer from diabetes and children from families without fathers were more likely to be obese.

In summary, a large number of studies have proved that fathers' participation has an irreplaceable important value in the development of children. Father involvement plays an important role in the development of children's personality and social development, cognition, intelligence and academic achievement, gender roles, morality and emotion, physical health and so on. Therefore, studies on how to improve the fathers' participation and how to participate effectively in children education and rearing are of great significance for the healthy development of children.

\section{Factors Affecting the Participation of Fathers}

Park (1996) classified the factors that affected fathers' participation into five categories: personality, children, family, culture, and public institutions, but did not take into account the interaction of these factors. Belsky (1984) integrated individual, social and cultural factors into the impact on parenting behavior, and took into account three aspects of interaction. He described three determined factors of parental upbringing: parents' characteristics, social background and children's characteristics. According to his study, the support of spouses was one of the key factors that determined the function of parents. In most societies, fathers were defined as breadwinners. Father involvement encountered prejudices from acquaintances, neighbors, relatives and co-workers. Social psychology studies have also found that when men take part in parenting activities in a different way than traditional ones, others may have negative views of them.

Xu Yan et al. (2006) showed that children's grades influenced their fathers' participation. First-grade fathers had more rules on their children than kindergarten classes and middle classes, but had nothing to do with children's gender differences. Wang Shuyun (1996), a Taiwanese scholar, made some analysis in several aspects. First, the definition and restriction of traditional gender division of labor had reduced the fathers' desire to raise children. Second, social education caused men to consider their parenting abilities inferior to those of women, and delegate responsibility for upbringing to mothers who he thought would do better. Third, using the logic of division of labor, the difference of parental roles was strengthened in the work structure and system, and the time fathers spent in child-rearing reduced. Fourth, social policy and welfare services limited the opportunities for fathers to participate in parenting. At present, "paternity" is almost equal to "mother duty". Books on parenting, though captioned by parents, focus on mothers in substance, ignoring the responsibility of fathers. Anqi Xu and Liang Zhang (2008) set up a comprehensive analysis model in the light of China reality, pointing out the socio-economic characteristics of fathers, gender culture and attitudes, parenting skills and feedback, both the internal and external environment of the family and the role of "gatekeepers" of mothers had practical impact on the participation of fathers. Ming Zhang (2011) summarized the factors influencing fathers' participation in upbringing into macro-level and micro-level. The macro-level mainly included social culture, social support and 
policy system and other factors. The micro-level mainly included fathers' age, education level, parenting attitude, motivation and other factors as well as children's gender, age, temperament and other external factors as well as mothers' attitude, occupation and other external factors.

According to the previous research results, the main influencing factors of fathers' participation were family factors, social factors, fathers personal characteristics and children characteristics. Among family factors affecting fathers' participation, fathers' marital satisfaction and mothers' support played a major role. Social factors included the division of traditional social roles, social traditional concepts and the social support of fathers' participation. Fathers personal characteristics mainly referred to their identities, professional knowledge of educating children, attitudes towards raising children, personality characteristics and so on. Children characteristics included their gender, temperament types, personality characteristics and so on. In addition, a small number of studies also mentioned the biological factors of father involvement, the influence of kindergarten and other educational institutions, as well as the influence of experts and scholars on fathers' participation.

\section{Analysis of Existing Researches}

In early 1980s, with the establishment of the theory of family system, fathers as an important pole of family education, entered the field of view of foreign researchers, and they began to study the role of fathers tentatively. The research in this stage mainly discussed the value of father education, explored and constructed the concept and structure of father involvement in upbringing, and made a simple investigation on the present situation of fathers' participation. The research scope was narrower and the research method was single. In 21st century, more and more researchers turned their attention to fathers, and separated the influence of father involvement in parenting on early childhood development from the influence of social classes and family structures. Taking fathers' participation in parenting as an independent factor to examine its influence on the development of young children. The scope of the study has been expanded gradually, not only on the significance of father involvement in upbringing on their own roles, but also on the factors that influence fathers' participation, and the influence of fathers' participation on couple co-rearing relationships, and so on. The impact of father involvement on the development of their children was further explored. The research methods got rid of the past single theoretical research and empirical investigation method, adopting many kinds of research methods, such as individual case, experiment, follow-up and so on, and made more scientific and systematic studies on the various factors of father involvement in upbringing. At present, there are few studies on father involvement in parenting in China. The scope of studies are mainly focused on the translation of foreign literatures and investigation of the present situation of domestic participation. The overall study is still in its infancy. It can be known from the above analysis that there is a lack of research on father participation in China compared with the previous studies abroad. The neglect of father participation in upbringing for a long time has led to the study of father participation in China is still in its infancy.

\section{Acknowledgement}

Fund project: Guizhou Provincial Department of Education 2016 Humanities and Social Sciences Youth Project "Innovation and Breakthrough: Path Research on Father's Participation in Education of Children" (No. 2016qn50). 2019 Joint Project of Theoretical Innovation in Guizhou Province "A study on the Promotion Strategy of Preschool Education legislation in China" (No.GZLCLH-2019-268).

\section{References}

Biller, H. (1981). Father Absence, Divorce, and Personality Development. In M. Lamb (Ed.), The Role of the Father in Child Development (2nd ed.). New York, NY: Wiley.

Biller, H. B. (1969). Father absence, maternel encouragement, and sex role development in kindergarten age boys. Child Development, 40(2), 539-545. https://doi.org/10.2307/1127421

Biller, H. B. (1993). Fathers and families: Paternal factors in child development. Westpot, CT: Auburn.

Chen, J. Q. (2002). Father Discovers: There is No Rule of Fathers' Love. Family Education, (11), 38-39.

Chen, J. Q. (2007). Paternal Education Should be Emphasized. Chinese Family Education, (1), 5.

Flour, E. (2005). Fathering and Child Outcomes (pp. 56-77). West Sussex, England: John Wiley \& Sons Ltd. https://doi.org/10.1002/9780470713228

Golda, S. G. (1993). Family Factors to Children's Intensic/Extrinsic Motivational Orientation and Academic Performance. Child Development, 1461-1474. https://doi.org/10.1111/j.1467-8624.1993.tb02964.x

Hao, J. F., \& Wang, Z. H. (2002). Bring into Play the Charm of Fatherly Love. Modern Tutor, (11). 
Harknett, K. (2005). Children's Elevated Risk of Asthma in Unmarried Families (pp. 19-27). Underlying Stueturaland Behavioral Mechanisms. Working Paper, 2005-01-FE. Princeton, NJ: Center for Research Child Well-being.

Henderson, A. T., \& Berla, N. (1994). A New Generation of Evidence: The Family is Critical for Student Achievement. Washington, DC: National Committee for Citizens in Education.

Hoffman, M. (1981). The Role of Father in Moral Internalization. In M. Lamb (Ed.), The Role of the Father in Child Development (2nd ed.). New York, NY: Wiley.

Jin, C. (2005). The Influence of Father on Children's Psychological Development. Basic Education Studies, (10).

Judy, H. (2001). Farrington D. Distinguishing the Link between Disrupted Families and Delinquency. British Journal of Criminology, 41(1), 22-40. https://doi.org/10.1093/bjc/41.1.22

Li, X. (2007). The Role of Fathers in the Development of Children's Personality. Law and Society, (6), 639.

McBride, B. A., Schoppe-Sullivan, S. J., \& Ho, M. (2005). The Mediating Role of Fathers' School Involvement on Student Achievement. Journal of Applied Development Psychology, 26(2), 201-216. https://doi.org/10.1016/j.appdev.2004.12.007

Parker, R. (2000). Father Roles. Shenyang: Liaohai Press.

Scott, J. D. (1995). Parent-child Interactions and School Achievement. In B. A. Ryan, G. R. Adams, T. P. Gullotta, R. P. Weissberg, \& R. L. Hampton (Eds.), The family-school connection (Vol. 2, pp. 75-109). Theory, research, and practice. Thousand Oaks, CA: Sage.

Stanley, B. K. (1986). The Effect of Father Absence on Interpersonal Problem-solving Skills of Nursery School Children. Journal of Counseling and Development, 64(6), 383-385. https://doi.org/10.1002/j.1556-6676.1986.tb01141.x

Stoop, D. (2005). Translated by Li Libo. Work with Dad_Discover the Role and Influence of Fathers. Kyushu Press.

Sun, Y. X. (2007). How to Be a Good Parent. Beijing: China Personnel Press.

Tamis-LeMonda, C. S. (2004). Conceptualizing Fathers Roles: Playmates and More. Human Development, 47(4), 220-227. https://doi.org/10.1159/000078724

Tao, S., \& Lin, L. (1994). A Study on Educational Style and Influence Factors of Mothers of 3 to 6 Years Old Children. Psychological Development and Education, (3).

Thomas, M. S., \& Ame, M. B. (1991). Parents and Teachers of Exceptional Students: A Handbook for Involvement. Allyn and Bacon Inc.

Trost, S. G., Kerr, L. M., Ward, D.S., \& Pate, R. R. (2001). Physical Activity and Determinants of Physical Activity in Obese and Non-obese Children. International Journal of Obesity, 25(6), 822-829. https://doi.org/10.1038/sj.ijo.0801621

Wang, Z. Y. (2004). Developmental Psychology of Preschool Children. Beijing: People Education Press.

Yu, S. (2011). A Study on the Relationship between Father Rearing Behavior and Social Behavior of 2-6-year-old Children. Shanghai: East China Normal University.

Zhang, C. X., \& Lin, Q. S. (1981). Educational Psychology. Taipei: Tung Wah Book Company.

Zhang, M. (2011). A Survey on Subjective Well-being of Urban Fathers in Participating in Parenting. Shanghai: East China Normal University.

Zhao, L. W. (2010). A Survey on the Phenomenon of Father Absence in Family Education and Its Counter Measures. Shanghai: East China Normal University.

\section{Copyrights}

Copyright for this article is retained by the author(s), with first publication rights granted to the journal.

This is an open-access article distributed under the terms and conditions of the Creative Commons Attribution license (http://creativecommons.org/licenses/by/4.0/). 